\title{
Impact of Survey Description, Administration Format, and Exclusionary Criteria on Population Prevalence Rates of Problem Gambling
}

\author{
Robert J. Williams ${ }^{1}$ and Rachel A. Volberg $^{2}$ \\ ${ }^{1}$ School of Health Sciences and Alberta Gaming Research Institute, University of Lethbridge, \\ Lethbridge, Alberta, Canada. ${ }^{2}$ Gemini Research, Northampton, Massachusetts, USA.
}

\begin{abstract}
The present study investigated the impact of survey administration format, survey description, and gambling behaviour thresholds on obtained population prevalence rates of problem gambling. A total of 3,028 adults were surveyed about their gambling behaviour, with half of these surveys administered face-to-face and half over the phone, and half of the surveys being described as a 'gambling survey' and half as a 'health and recreation' survey. Population prevalence rates of problem gambling using the CPGI were 133\% higher in 'gambling' versus 'health and recreation' surveys and 55\% higher in face-to-face administration compared to telephone administration. If people with less than $\$ 300$ in annual gambling expenditures are not asked questions about problem gambling, then the obtained problem gambling prevalence rate is $42 \%$ lower. When all of these elements are aligned they result in markedly different problem gambling prevalence rates ( $4.1 \%$ versus $0.8 \%)$. The mechanisms for these effects and recommended procedures for future prevalence studies are discussed.
\end{abstract}

Key Words: problem gambling; prevalence; modality; administration format; survey description

International Gambling Studies, 2009, 9(2), 101-117

${ }^{1}$ Robert.williams@uleth.ca 


\section{Introduction}

In 2002, Statistics Canada conducted the first national prevalence study of problem gambling in Canada as part of the Canadian Community Health Survey (CCHS) (Mental Health $\&$ Well-Being; Cycle 1.2). As is typical for Statistics Canada, both the sample size $(36,984)$ and the response rate $(77 \%)$ were excellent. However, there was considerable surprise associated with their finding that the overall past year Canadian prevalence of moderate plus severe problem gambling of $2.0 \%$ (using the Canadian Problem Gambling Index, CPGI) was about $80 \%$ less than what had been obtained from nine provincial problem gambling prevalence studies that had been conducted in roughly the same time period (2001 to 2003) (see Table 1).

There are three important differences between the national and provincial studies that might explain this discrepancy. The first concerns a difference in administration format. The large majority (86\%) of the Statistics Canada CCHS 1.2 survey was done face-to-face at the person's residence using a 'Computer-Assisted Personal Interview' (CAPI) procedure, whereas all of the provincial studies were done over the telephone using a 'Computer-Assisted Telephone Interview' (CATI) procedure. (Rates of CAPI utilization were 62.3\% in CCHS 2.1 in 2003 and $78.6 \%$ in CCHS 3.1 in 2005).

Self report of sensitive subject matter (e.g., substance use, sexual behaviour) is known to be strongly influenced by respondents' perceptions of how positively or negatively others (particularly the interviewer) will evaluate their responses (Fowler, 1993; Schaeffer, 2000; van der Heijden et al, 2000). Consequently, administration formats that provide more anonymity (e.g., self-administered surveys) generally obtain more valid reports of socially sensitive behaviour (see Tourangeau \& Yan, 2007 for a review). Thus, it is quite possible that the face-toface format used in CCHS may have produced some under-reporting of problem gambling. The fact that Statistics Canada also asked all participants for their name, address, telephone number and date of birth at the outset of each interview may have exacerbated this problem, as might the fact that $13 \%$ of the interviews were conducted with other family members present. Although this 'social desirability effect' has never been investigated or documented for gambling behaviour, it seems a plausible explanation for the obtained differences.

The impact of CCHS administration format has been investigated for some health indicators (but not gambling) by Statistics Canada researchers (St-Pierre \& Beland, 2004). Several significant differences were obtained in self-reported health behaviours between the telephone-based interview (CATI) and the face-to-face interview (CAPI). The results are complex, and vary as a function of the variable examined, as well as age, ethnicity, income group, province, and question sensitivity. However, it is interesting to note that Statistics Canada researchers did not obtain higher rates of behaviour on ostensibly 'sensitive' questions in CATI versus CAPI administration (i.e., consuming 5 or more drinks on one occasion; fair or poor mental health; smoking status). Furthermore, there was a tendency for some 'sensitive' questions to produce higher rates with CAPI administration (i.e., self-reported height and weight). It would appear that the opportunity for objective (i.e., visual) verification in the CAPI administration may produce more valid reports in some situations. Furthermore, it is possible that face-to-face administration may foster better rapport, which may favour more valid responses. Indeed, existing research tends to support the contention that more candid responding occurs with face-to-face over telephone administration in most circumstances (see Holbrook, Green \& Krosnick, 2003; Tourangeau \& Yan, 2007 and the meta-analysis by de Leeuw \& van der Zouwen, 1988). 
Thus, it seems clear that administration format does impact self-report, but that no presumptions can be made about the nature or direction of this impact on gambling behaviour without a direct test.

The second important difference between the national and provincial studies of problem gambling concerns potential sampling bias. Although the Statistics Canada survey was not compulsory, it nonetheless obtained a response rate of $77 \%$, considerably higher than the $20 \%-$ $50 \%$ rates obtained in the provincial studies. ${ }^{2}$ People who participate in surveys tend to differ in systematic ways from people who opt not to participate, with this risk of nonrepresentativeness generally increasing with lower response rates (Groves, 2006; Groves et al., 2006). In general, males refuse more than females (Smith, 1983); urban dwellers refuse more than rural dwellers (de Leeuw \& de Heer 2002); adults who live alone have higher refusal rates than large households (Groves \& Couper 1998); and households with young children have higher response rates than others (Lievesley, 1988). These demographic biases are well known and are often addressed by post-hoc weighting. However, there is no guarantee that these adjustments successfully address the bias (Brick, Le \& West, 2003; Little \& Vartivarian, 2003).

Another primary reason for survey nonparticipation is lack of interest in the topic (Groves, Presser \& Dipko, 2004; Groves et al., 2006; Tourangeau \& Yan, 2007). For example, Groves et al. (2006) showed that teachers participated at a much higher rate in a telephone survey described as being on "Education and the Schools" than in one described as being on "Issues Facing the Nation" (56\% versus 39\%). Topic disinterest is virtually never taken into account or adjusted for in surveys even though it has an obvious potential for biasing the data. It is important to note that all of the provincial gambling studies were described as 'gambling surveys' whereas the Statistics Canada study was described as a study assessing 'well-being and health practices' (as gambling behaviour was only one component of the survey). Thus, in the provincial studies it is quite possible that gamblers participated at a higher rate because of their greater interest in the topic, resulting in an artifactually high obtained prevalence of gambling (and consequently, problem gambling) among the participants. Support for this is seen in the fact that the provincial surveys obtained an average past year gambling prevalence rate of $81.9 \%$ compared to $76.0 \%$ for the CCHS (Canadian Partnership for Responsible Gambling, 2005).

The third important difference between the national and provincial studies of problem gambling concerns a difference in the threshold for asking questions about problem gambling. The provincial surveys tended to ask questions about problem gambling of everyone who reported any gambling in the past year, regardless of frequency and expenditure. However, the CCHS surveys used a higher threshold in that they did not administer questions about problem gambling to a) anyone who said 'they were not a gambler' even if they had reported gambling expenditures in the past 12 months; and/or b) respondents who reported gambling no more than 5 times for each type of gambling in the past year. As a consequence of this difference, the provincial problem gambling prevalence numbers include a small but significant number of people who score in the past year problem gambling range, but who report minimal past year gambling involvement. It is unclear whether these are legitimate past year problem gamblers who failed to accurately convey their gambling expenditures, or people who misinterpreted the problem gambling questions (perhaps reporting a 'lifetime' rather than a 'past year' history of problem gambling). If it is the former, then the Statistics Canada prevalence

\footnotetext{
${ }^{2}$ This is not an unusual result, as response rates are usually higher in central government surveys relative to academic or nonacademic surveys (Groves \& Couper, 1998).
} 
figures are artifactually low. If it is the latter then the provincial prevalence figures are artifactually high. ${ }^{3}$

The true population prevalence of problem gambling is a very important index of the impact of legalized gambling, as well as the effectiveness of policies designed to mitigate associated harm. Valid estimates of problem gambling are also essential for priority setting in research, policy, and prevention and treatment service development and funding. One of the primary purposes of the present project is to determine the relative impact of administration format, survey description, and 'thresholds' for asking problem gambling questions on obtained rates of problem gambling, so as to speak to the relative validity of the national and provincial rates that have been reported. However, a second and equally important purpose is to identify 'best practices' in conducting future problem gambling prevalence studies. 'Best practices' is a particularly pertinent issue today, in light of declining telephone response rates, increased exclusive use of cell phones, increased use of multiple land-lines, national 'do-not-call' registries, and the increasing use of online surveys (de Leeuw \& de Heer, 2002; de Leeuw, 2005; Volberg, 2007).

\section{Methodology}

\section{Sample and Procedure}

A sample of 3,028 adults was surveyed by the Survey Research Centre (SRC) at the University of Waterloo between January 10, 2008 and April 14, 2008. The study was conducted in the Kitchener Census Metropolitan Area (CMA) in Ontario, Canada. The Statistics Canada 2006 census shows the Kitchener CMA to be a geographic region of 827 square kilometers with a population of 451,235 and 177,879 private dwellings. It is composed of the three cities of Kitchener, Waterloo, and Cambridge, and the two townships of North Dumfries and Woolwich (see Figure 1).

The Kitchener CMA was chosen for two reasons. The first was to create a small enough geographic region to make door-to-door surveys logistically feasible. The second was to ensure a good base rate of problem gambling. The Kitchener CMA had one of the highest rates of problem gambling in Ontario in the CCHS 1.2 survey (3.6\% compared to $2.0 \%$ for the rest of Ontario; Rush et al., 2005). The reason for this is uncertain, although this CMA does have the youngest median age in Ontario, partly due to one college and two universities in the area (University of Waterloo, Wilfred Laurier University, Conestoga College). Furthermore, college and university students have one of the highest documented past year rates of problem gambling ( 7 or $8 \%$ ) (Shaffer \& Hall, 2001; Williams et al., 2006).

The sample was selected in one of two ways. Seventy one percent were randomly selected from Census Dissemination Areas (DA) having a higher than average prevalence of people aged $20-29$ (15\% was the minimum needed prevalence), as this is the age group that generally has the highest rate of problem gambling. Twenty nine percent came from a random selection of areas of two-kilometer diameter within the Kitchener CMA. Within each of these

\footnotetext{
${ }^{3}$ It is interesting to note that the Quebec 2002 provincial study (Ladouceur et al., 2005) also utilized a high gambling threshold before asking problem gambling questions (i.e., person had to have spent more than $\$ 520$ annually on gambling or have 'played too much', 'spent too much money', or 'spent too much time gambling'), and it is one of the few provincial studies that obtained problem gambling rates comparable to the CCHS.
} 
circumscribed geographic areas, a comprehensive listing of listed phone numbers that had accompanying addresses was compiled. ${ }^{4}$ These listings were randomly assigned to either telephone recruitment or door-to-door recruitment. Within each modality, the sample was then randomly assigned to receive either a 'gambling' or 'health and recreational activities' description of the survey (even though the surveys were otherwise identical). Thus, there were four different groups: the Telephone Gambling Survey (TG) group; Telephone Health \& Recreational Survey (THR) group; Face-to-Face Gambling Survey (FG) group; and the Face-toFace Health \& Recreational Survey (FHR) group. Recruitment continued until there were at least 1,500 people in each of the two different administration formats and each of the two different survey description groups.

In advance of the actual recruitment, a postcard was delivered to most of the selected neighborhoods to alert people to our study in hopes of producing a better response rate (e.g., de Leeuw et al., 2005). Addresses assigned to the door-to-door approach were grouped together by streets for logistical ease. Face-to-face surveys were administered via a Palm III handheld device. For logistical and safety reasons, a second interviewer was usually present for the faceto-face interviews (but was silent and stayed in the background). The telephone surveys were administered using WinCATI software in the SRC telephone lab. The majority of contacts were made in the evening and on weekends.

The interviewee was randomly determined by requesting the interview be conducted with the adult (18+) in the household having the most recent birthday. If this person was not available, the person having the last birthday was interviewed. If this person was not available, the person answering the door was interviewed. There were only three attempts to interview someone in the household due to the logistical costs involved in returning to the person's house for a face-to-face survey. Although additional contact attempts could easily have been made for the telephone surveys, this was not done in order to make the sampling procedure equivalent to the face-to-face protocol.

\section{Questionnaire}

The questionnaire was introduced as follows: "Hello, I'm conducting a short 10-15 minute survey on gambling (or 'health and recreational activities') on behalf of the Survey Research Centre at the University of Waterloo. Do you have a couple of minutes?" People who said they do not gamble were told "we are just as interested in opinions of both non-gamblers and gamblers". People asking about the types of recreational activities were told "leisure activities such as gambling".

The questionnaire took between 10 and 15 minutes and had six sections:

1. Validity Questions. The 12 questions that began the survey had two purposes. The first was to provide some transitioning for people who received the 'health and recreation' description, as almost all of the validity questions asked specifically about general health or recreational behaviour. The second purpose was to gauge the relative validity of responses provided face-to-face versus over the phone. Hence, some questions asked about nonsensitive issues where no response distortion was expected (e.g., general health status; movie theatre attendance). Some questions asked about sensitive issues where response distortion was anticipated (e.g., frequency of illicit drug use; frequency of driving while intoxicated; voting

\footnotetext{
${ }^{4}$ ASDE Survey Sampler (from whom the sample was purchased) indicated that approximately $2 \%$ of listed numbers had no accompanying address.
} 
in the past provincial election). Some questions investigated whether the person may have an enduring pattern of positive or negative impression management (whether they had 'ever' been ill; number of pleasant memories from childhood). Finally, some questions were designed to assess response acquiescence, not paying attention, or flippancy (lacrosse being their favorite sport to watch on TV; Arctic being their preferred vacation destination).

2. Gambling Behaviour. Information was obtained on the frequency and expenditure for nine types of gambling, using questions with optimal wording for obtaining this information (i.e., Wood \& Williams, 2007).

3. Problem Gambling. The problem gambling section was asked of everyone who reported any past year gambling. It consisted of the 29 unique questions that comprise the Canadian Problem Gambling Index (CPGI) (Ferris and Wynne, 2001) ${ }^{5}$, South Oaks Gambling Screen (SOGS) (Lesieur \& Blume, 1987), NORC DSM-IV Screen for Gambling Problems (NODS) (Gerstein et al., 1999), and the Problem and Pathological Gambling Measure (PPGM). All of these instruments used a past year time frame. The CPGI has very good internal consistency (alpha $=.89)$ and good test-retest reliability $(r=.78)$. Criterion validity is established by its correlation $(r=.83)$ with the SOGS and DSM-IV. Construct validity of the CPGI is established by its significant correlations with gambling involvement. The SOGS has excellent internal consistency $($ alpha $=.97)$ and reasonably good test-retest reliability $(r=$ .71). Criterion validity is established by its correlation with the DSM-III-R $(r=.94)$. The NODS has excellent test-retest reliability $(r=.98)$ and is known to have good correspondence with clinically assessed pathological gamblers. The PPGM is an experimental measure of problem gambling under development by the first author. Its reliability and validity is still being investigated. The order of the four instruments was randomized and, once a question was asked, its equivalent question in the other scale(s) was not asked. There were an additional two questions that inquired whether the person had any history of problem gambling prior to the past 12 months and whether the person had ever sought help for problem gambling. Note that although four different problem gambling scales are used, the focus of the present study is on the CPGI, as we are trying to resolve differences between Canadian provincial CPGI rates and the national CPGI rate. The primary purpose of administering all four scales was to comprehensively ask all questions potentially relevant for the clinical assessment of problem gambling in our clinical validation procedure (see below).

4. Inconsistency Questions. The questionnaire was programmed to prompt the interviewer to ask an additional open-ended question if the person provided a pattern of answers whereby a) he/she had a score of 3 or more on the CPGI in the absence of at least $\$ 300$ in past year gambling losses, or $b$ ) the person had an aggregated past year gambling loss of $>\$ 1,000$ but scored 0 on the CPGI. The question in the first situation was "I notice you report having some potential problems with gambling, but your total reported loss in the past 12 months is less than $\$ 300$. Can you explain?" The question in the second situation was "I notice you report having lost over $\$ 1000$ to gambling in the past 12 months, but don't report any problems or concerns with this. Can you explain?" The purpose of these questions was to shed light on the validity of the obtained CPGI categorizations for the small percentage of people with these inconsistent patterns.

\footnotetext{
${ }^{5}$ In the case of the CPGI, only the nine items that comprise the scored Problem Gambling Severity Index (PGSI) were included.
} 
5. Participant Demographics. Specifically, age, gender, marital status, highest level of education, employment status, household income, household debt, immigrant status, and ethnicity.

6. Interviewer Demographics. Age, gender, and ethnicity. ${ }^{6}$

\section{Results}

The results of this study are reported in Table 2. With regard to administration format, the pattern of CPGI categorizations (nongambler, nonproblem gambler, low risk gambler, moderate problem gambler, severe problem gambler) was significantly different between Telephone administration and Face-to-Face administration, $\chi^{2}(4)=25.6, p<.001$. A $z$ test of column proportions ( $p<.05$ with Bonferroni adjustment for multiple comparisons) further determined that Face-to-Face administration produced a significantly higher percentage of gamblers, low risk gamblers, and moderate problem gamblers.

There appear to be two separate mechanisms that contribute to this effect. The primary mechanism is that face-to-face administration results in increased participation of demographic groups with higher rates of gambling and problem gambling. More specifically, relative to the Telephone administration group, the Face-to-Face group recruited significantly more: single people, $\chi^{2}(5)=109.4, p<.001$; fulltime students, $\chi^{2}(2)=69.7, p<.001$; males, $\chi^{2}(1)=26.4, p<$ .001 ; immigrants, $\chi^{2}(1)=17.8, p<.001$; younger people, $t(2958)=13.1, p<.001$; and people with lower incomes, $t(2603)=2.97, p=.003$.

It is fairly common practice to conduct post-hoc data weighting to correct for demographic biases in the obtained sample. However, even when this is done, Table 3 shows that there are still higher rates of gambling and moderate problem gambling in the Face-to-Face format $(p=.056)$. Differences in responses to the validity questions between the two administration formats suggest this is due to more honest/candid responding in the Face-to-Face group. Analysis of covariance (ANCOVA) was conducted on each of the validity questions, entering all significant demographic differences as covariates (Chi square tests were conducted on the two questions with nominal level answers). ${ }^{7}$ People in the Face-to-Face group reported significantly lower rates of voting $(61 \% \text { versus } 72 \%)^{8} F(6,2978)=71.3, p=.000$; a higher frequency of driving while intoxicated $F(6,2974)=59.85, p=.000$; a higher frequency of illicit drug use $F(6,2988)=59.31, p=.000$; a higher rate of alcohol use $F(6,2974)=33.44, p=.000$; a lower rate of serious mental health problems $F(6,3003)=6.27, p=.000$; a lower frequency of exercising $F(6,3005)=4.42, p=.000$; and better general health $F(6,3005)=3.31, p=.003$. A $z$ test of column proportions also showed that significantly more people in the Telephone group reported their preferred vacation destination to be the Arctic $(p<.05)$. Although not technically

\footnotetext{
${ }^{6}$ The impact of interviewer characteristics is not reported in the present paper because these variables were not balanced across conditions. In any case, analysis of gender and ethnicity failed to show a consistent pattern of effects on problem gambling prevalence rates, although there was a tendency for higher rates of problem gambling with male interviewers.

${ }^{7}$ The ANCOVA procedure permits all six confounding demographic variables to be controlled for whereas conducting ANOVA and Chi Square tests after SPSS data weighting only controls for the three demographic variables that have been weighted.

${ }^{8} 51 \%$ of adults in the Kitchener CMA voted in the 2007 provincial election.
} 
a validity question, it is also worth noting that significantly more people in the Telephone group refused to divulge their income $(17 \%$ versus $11 \%)(p<.05)$.

Survey description also produced a significantly different pattern of CPGI categorizations, $\chi^{2}(4)=26.2, p<.001$. A $z$ test of column proportions $(p<.05)$ with Bonferroni adjustment determined that the Gambling survey produced a significantly higher percentage of gamblers, low risk gamblers, and moderate problem gamblers compared to the Health and Recreation survey. As seen in Table 3, this same effect appears even after appropriate weighting, $\chi^{2}(4)=33.7, p<.001$. The mechanism for this effect appears to be simply that a greater proportion of gamblers participated in the Gambling survey, presumably because of greater intrinsic interest. This is further corroborated by the fact that $10.9 \%$ (238/2188) of the Gambling survey refusals spontaneously indicated they were not participating because they do not gamble or have no interest in gambling. ${ }^{9}$ Unlike the administration format, survey description did not affect the demographic mix of people in the Gambling survey versus the Health and Recreation survey. There were also no significant differences in any of the validity questions, with one exception: people in the Health and Recreation survey reported having significantly worse health status compared to people in the Gambling survey, $F(1,3018)=16.54, p=.000$. It would seem that, similar to the gambling survey effect, 'health' surveys appear to disproportionately attract people with health concerns.

The other comparisons in Tables 2 and 3 document that the same survey description effect also occurs just within people who received Telephone administration, and just within people who received Face-to-Face administration. Similarly, the same format administration effect tends to occur for people who just received a Gambling survey description, and for people who just received a Health and Recreation description. The one exception is the Telephone Gambling Survey versus the Face-to-Face Gambling Survey comparison, where there are no significant differences after weighting. This again reflects the fact that the primary mechanism for the face-to-face administration effect is the increased participation of demographic groups with higher rates of gambling and problem gambling.

The focus of our study was the impact of administration format and survey description on the CPGI rates of problem gambling. However, it is instructive to examine whether the same effects occur with the other assessment instruments (SOGS, NODS, PPGM) and with raw scores as well as derived categorical rates. Hence, a series of 2 way Analysis of Variance (ANOVAs) were conducted using raw scores and categorical rates for each of the four instruments. ${ }^{10} \mathrm{~A}$ similar pattern of results emerges, as can be seen in Table 4. A significant main effect of survey description is obtained in all instruments for both raw scores and derived categories and for both unweighted and weighted data. For administration format, a significant main effect is obtained for all instruments for both unweighted raw scores and derived categories. However, a significant main effect is no longer found for CPGI, SOGS, or PPGM raw scores after appropriate weighting to improve the demographic representativeness of the telephone format. Of final note, almost none of the Format x Description interaction effects are statistically significant.

A final issue concerned the impact of different gambling behaviour thresholds used to determine whether to ask people the problem gambling questions. In the present study, anyone

\footnotetext{
${ }^{9}$ The SRC was asked to record any stated reasons for nonparticipation.

${ }^{10}$ This is not an optimal statistical approach, as there is severe and uncorrectable skewness, kurtosis, and heterogeneity between the groups, which violates the statistical assumptions of ANOVA. However, violation of these assumptions may still produce valid results with large sample sizes, as we have in this study.
} 
who had any gambling behaviour in the past year (i.e., $72 \%$ or $2193 / 3028$ people), was asked all of the problem gambling questions. This resulted in $2.9 \%(89 / 3028)$ of the total sample scoring in the moderate or severe problem gambling range on the CPGI (2.6\% with weighting). In most surveys (including all of the aforementioned provincial surveys), all of these people are assumed to be problem gamblers. ${ }^{11}$ However 43 of these 89 people reported having aggregate net gambling losses of less than $\$ 300$ in the past year. If these individuals had been automatically excluded from the problem gambling section, the obtained prevalence rate would have been reduced to $1.5 \%$ (with weighting).

To shed light on the true problem gambling status of these 43 people, they were specifically asked to explain the discrepancy between their expenditures and their reports of problems. Two clinical psychologists then examined these verbatim explanations, along with a comprehensive profile of the person's past year gambling behaviour (types, frequencies, expenditures); his/her answers to the 31 problem gambling questions (no aggregated scale scores were provided); his/her answers to the 12 validity questions; and certain relevant demographic variables (person's age, household debt, household income, current employment status, current marital status). These clinicians then independently assessed the person's problem gambling status using a commonly accepted definition: "Problem gambling is characterized by difficulties in limiting money and/or time spent on gambling which leads to adverse consequences for the gambler, others, or for the community." (Gambling Research Australia, 2005). Using this procedure, $60 \%$ (26/43) of individuals with this discrepancy were judged to be genuine problem gamblers. For the majority of these people, their low net gambling expenditure was a result of their claiming to typically win large amounts most months for certain types of gambling (a statistically unlikely scenario) that offset their losses in other types. Of the $40 \%$ (17/43) of individuals who were judged not to be problem gamblers, most reported very little gambling involvement and had minimal symptomatology on the CPGI (all but two had a CPGI score of 3 or 4), suggesting that the CPGI thresholds for moderate problem gambling may be too low. There was one individual with a CPGI score of 12 despite not reporting any past year gambling. It is interesting to note that this person reported having a history of problem gambling prior to the past 12 months, which may have influenced his responses to the CPGI past year questions.

The other type of discrepancy is represented by the 114 people who reported a past year gambling loss of over $\$ 1000$ without any accompanying problems (CPGI score of 0 ). These individuals were clinically assessed in the same manner described above. In the absence of any self report of problems or loss of control, it is very difficult to judge anyone to be a problem gambler. Furthermore, none of these individuals admitted to problems when confronted with the discrepancy (although it is important to note that $18 \%$ refused to answer the question or had no comment about the discrepancy). In all, the clinicians determined that only $4 \%$ of individuals had gambling expenditures and frequencies that were unambiguously excessive relative to their income, debt, employment status, marital status, and age, and were therefore 'probable problem gamblers' (in denial). Another $22 \%$ were judged to be 'at risk', as they were spending thousands of dollars a year on gambling when their income and current debt would suggest this was unwise. However, the large majority of these people (74\%) were judged to be nonproblem gamblers. Most of these individuals had relatively low expenditures (i.e., just over $\$ 1,000$ ) relative to their income and debt. Many of these individuals indicated that the past year aggregate expenditure total we had calculated from their monthly gambling on each form was

\footnotetext{
${ }^{11}$ Obviously, this assumption may not be well founded, as these individuals have not been clinically assessed. Furthermore, there is still considerable debate as to the clinical significance of the CPGI moderate problem category.
} 
too high. A significant percentage of these people (26\%) only engaged in the buying and selling of high risk stocks.

\section{Discussion}

Survey administration format, survey description, and gambling behaviour thresholds were all found to significantly and independently influence problem gambling prevalence rates. Survey description appears to be the strongest of these effects, with rates of moderate and severe problem gambling being 133\% higher in 'gambling' surveys. The apparent mechanism for this effect is that gamblers and problem gamblers are intrinsically more interested in 'gambling' surveys and therefore participate at a much higher rate than nongamblers. Administration format is the next strongest effect, with face-to-face administration producing rates that are $55 \%$ higher than telephone administration. This is primarily due to face-to-face administration resulting in increased participation of demographic groups (young people, males) that tend to have higher rates of gambling and problem gambling (partly due to fewer young people being contactable with the telephone administration format because of only having cell phones). A secondary mechanism is that face-to-face interviewing appears to elicit more candid/honest responding relative to telephone interviewing. Finally, if people with less than $\$ 300$ in annual gambling expenditures are excluded from being asked the problem gambling section, then the obtained prevalence rate of problem gambling is $42 \%$ lower.

When these variables are aligned, they result in radically different problem gambling prevalence rates, even after appropriate weighting to match the sample to the demographic characteristics for the population. A 'gambling survey' description, face-to-face administration, and only excluding individuals without any past year gambling behaviour produces a CPGI moderate and severe problem gambling prevalence rate of $4.1 \%$. However, when using a 'health and recreation survey' description, telephone administration, and excluding any individuals with less than $\$ 300$ in annual losses, the obtained prevalence rate is only $0.8 \%$.

The above findings help explain the lower problem gambling prevalence rate found in the 'well-being and health practices' Statistics Canada CCHS 1.2 study (using face-to-face interviewing) compared to the provincial telephone 'gambling' surveys conducted during the same time period. In the present study, the rate of problem gambling in the telephone 'gambling survey' group (2.9\%) is $32 \%$ higher than in the face-to-face 'health and recreation survey' group $(2.2 \%)$. This difference would almost certainly be much higher if the response rate in the face-

to-face format was closer to that obtained with CCHS 1.2. Although the face-to-face 'health and recreation' group had a comparatively high cooperation rate of $48 \%$, it is far from the $77 \%$ response rate obtained in the CCHS 1.2. Finally, this difference would also have been slightly higher if the gambling behaviour threshold used in the CCHS study were applied. However, it is important to remember that the CCHS study used a gambling frequency exclusion, rather than a monetary one (i.e., CCHS did not ask problem gambling questions of people who reported gambling no more than five times for each type of gambling in the past year). Using a similar frequency exclusionary criterion in the present study (i.e., not asking problem gambling questions of people who gambled 10 times or less for each type of gambling in the past year) would have only reduced the weighted prevalence rate from $2.6 \%$ to $2.3 \%$. Furthermore most of the exclusions would be appropriate, as only one of the nine individuals excluded in this fashion 
was clinically judged to be a genuine problem gambler. The eight other individuals had low CPGI scores of 3 or 4 as well as minimal gambling expenditure.

In conclusion, the present results indicate that obtained problem gambling prevalence rates are very much a function of how the survey is conducted. The obvious implication is that prevalence rate differences between studies could just as easily be the result of procedural differences as due to true differences in population prevalence. The extent to which these procedural differences are actually responsible for the different rates found in different studies is uncertain. Fortunately, this may not be a serious problem, as the large majority of these studies have used similar procedures and so have the same biases (i.e., telephone administration, 'gambling survey' description, and using any past year gambling as the only exclusionary criterion).

A more serious concern is that the present results also suggest that the population prevalence rates obtained in most previous studies may not be totally accurate. Determining the 'true' rate of problem gambling is a difficult task. However, it is clear that surveys with more accurate rates of problem gambling will be the ones using procedures that:

- Achieve a good overall response rate. In the present study, the cooperation rate in faceto-face administration (48.6\%) is clearly superior to telephone administration (35.7\%).

- Minimize known sampling bias. The face-to-face format produces a more representative demographic because of its ability to better recruit young people and males, demographic groups almost always under-represented in telephone surveys. Although there were no major demographic differences between the 'health and recreation' versus 'gambling' survey, it is apparent that a disproportionate percentage of gamblers participate in a 'gambling' survey. Hence, it is reasonable to assume that a 'health and recreation' survey is more likely to contain a more representative group of both gamblers and nongamblers.

- Produce the least response distortion. The present study confirms prior research showing that face-to-face administration favours more candid/valid reporting, possibly because it may foster better rapport (de Leeuw \& van der Zouwen, 1988; Holbrook, Green \& Krosnick, 2003; Tourangeau \& Yan, 2007).

- Do not erroneously exclude genuine problem gamblers or include non-genuine problem gamblers. Requiring a past year gambling expenditure of $\$ 300$ to be asked questions about problem gambling is too restrictive, as it has the effect of inappropriately excluding a substantial number of genuine problem gamblers. Thus, utilizing a more generous criterion to be asked problem gambling questions (i.e., any gambling in past year regardless of expenditure) is preferable. Alternatively, an even better solution may be the use of an exclusionary criterion based on a minimal frequency. Not asking problem gambling questions of people who gambled less than 10 times for each type of gambling in the past year has a much more modest impact on the overall prevalence rate and the vast majority of excludees are nongenuine problem gamblers who should be excluded.

Thus, face-to-face surveys that are not specifically introduced or described as gambling surveys (e.g., 'health and recreation survey') and that use liberal thresholds for asking problem gambling questions (any past year gambling behaviour or minimal gambling frequency) are likely obtain the most accurate rates of problem gambling. In the present study, these procedures produced a $2.2 \%$ prevalence rate. This is $32 \%$ lower than the $2.9 \%$ obtained with telephone 
interviewing and a 'gambling survey' description, which are the procedures that have been used in most prior prevalence studies.

Although prior problem gambling prevalence rates may be somewhat inflated, ${ }^{12}$ it is unclear whether future prevalence studies should be doing anything differently. The reality is that jurisdiction-wide face-to-face surveys are very costly and logistically difficult to administer. Also, when the survey's primary interest is in gambling behaviour, it is somewhat deceptive and misleading to describe the survey as anything but a 'gambling' survey. Finally, a change in prevalence is equally, if not more important, than knowing precisely what the true rate is. The large body of prior studies that have used telephone 'gambling surveys' with liberal criteria for asking problem gambling questions serves as a very useful benchmark to compare prevalence rates between jurisdictions as well as make comparisons between different time periods within the same jurisdiction. Changing procedures at this point would make these future comparisons much more difficult.

Instead, we believe the most reasonable approach is to: a) acknowledge that previously obtained rates may be somewhat higher than they should be; b) acknowledge the importance of procedural variables in shaping obtained problem gambling prevalence rates; c) ensure that all future studies routinely contain a detailed description of response rates, survey description, administration format, exclusionary criteria, and all other potentially relevant procedural details; d) employ the same procedures as prior studies when the primary interest is to compare changes relative to these prior studies; and e) conduct periodic face-to-face surveys that inquire about a wide range of issues (including gambling) to get a more accurate estimate of 'true' problem gambling prevalence rates and to better contextualize the findings of these other studies (or add a standardized gambling module to large omnibus health surveys like the CCHS).

In terms of future research, there would be significant value in replicating the present findings; comparing the relative validity of self-administered surveys; and comparing the relative validity of online survey administration.

\footnotetext{
12 The point is sometime made that telephone surveys likely under-represent problem gamblers because they are less likely to be home, less likely to answer the phone, and more likely to be incarcerated, in residential treatment, or in military service. While there is some truth this, it is not as strong an effect as one might expect. The first author has conducted two large scale prevalence studies (Williams \& Wood, 2007b, $n=6,654$; Wood \& Williams, 2009, $n=$ 8450) that used exhaustive telephone contact attempts (up to 36 in the first study and 48 in the second study) over several months (12 months in the first study and 18 in the second study) and found that the average number of telephone calls to establish contact is only somewhat higher for problem gamblers compared to nonproblem gamblers (5.5 versus 4.9) and that $95 \%$ of contactable problem gamblers are contacted by 16 attempts (versus 14 for nonproblem gamblers). Furthermore, when adjustments are made for problem gamblers who are incarcerated, hospitalized, in residential treatment, or in the military, the problem gambling prevalence rate is only marginally changed (i.e., increases by $\sim .03 \%$ ).
} 


\section{Acknowledgments}

The authors would like to thank the Survey Research Centre at the University of Waterloo for their skillful and thoughtful implementation of this study as well as the Ontario Problem Gambling Research Centre for their generous financial support for this work. 


\section{References}

Brick, J. Michael, David Ferraro, Teresa Strickler, and Carin Rauch. 2003. No. 8: 2002 NSAF Response Rates. Washington, DC: Urban Institute. Available online at http://www.urban.orgUploadedPDF/900692_2002_Methodology_8.pdf (accessed October 25, 2007).

Canadian Partnership for Responsible Gambling (2005). Canadian Gambling Digest 2004-2005. Retrieved from the Canadian Partnership for Responsible Gambling web site http://www.cprg.cal.

de Leeuw, Edith D. (2005). To mix or not to mix: Data collection modes in surveys. Journal of Official Statistics, 21 (2), 233-255.

de Leeuw, E., and de Heer, W. (2002). Trends in Household Survey Nonresponse: A Longitudinal and International Comparison. In Survey Nonresponse, ed. Robert M. Groves, Don A.Dillman, John L. Eltinge, and Roderick J. A. Little, pp. 41-54. New York: Wiley.

de Leeuw, Edith, Hox, J., Korendijk, E., and Lensvelt-Mulders, G.. (2005). The Influence of Advance Letters on Response in Telephone Surveys: A Meta-Analysis." Unpublished manuscript. Cited in Groves (2006).

de Leeuw, Edith D. and van der Zouwen, J. (1988). Data quality in telephone and face to face surveys: A comparative meta-analysis. In R. Groves, P. Biemer, L.Lyberg, J. Massey, W.Nicholls, and J. Waksberg (eds). Telephone Survey Methodology (pp 283-299). New York: Wiley.

Ferris, J., and Wynne, H. (2001). The Canadian Problem Gambling Index: Final Report. Submitted to the Canadian Centre on Substance Abuse. February 19, 2001.

Fowler, F.J. (1993). Survey Research Methods, Second Edition. London: Sage.

Gambling Research Australia (2005). Problem Gambling and Harm: Towards a National Definition. Commissioned for the Ministerial Council on Gambling. Prepared by the SA Centre for Economic Studies with the Department of Psychology, University of Adelaide. November 2005.

Gerstein, D., Volberg, R., Toce, M., Harwood, H., Johnson, R., Bule, T., et al. (1999). Gambling Impact and Behavior Study: report to the National Gambling Impact Study Commission. Chicago: National Opinion Research Centre.

Groves, R.M. (2006). Nonresponse rates and nonresponse bias in household surveys. Public Opinion Quarterly, 70 (5), 646-675.

Groves, R.M., and Couper, M. (1998). Nonresponse in Household Interview Surveys. New York: John Wiley. 
Groves, R.M., Couper, M.P., Presser, S., Singer, E., Tourangeau, R., Piani Acosta, G., Nelson, L. (2006). Experiments in producing nonresponse bias. Public Opinion Quarterly, 70 (5), 720-736.

Groves, R.M., Presser, S., and Dipko, S. (2004). The role of topic interest in survey participation decisions. Public Opinion Quarterly, 68 (1), 2-31.

Holbrook, A.L., Green, M.C., Krosnick, J.A. (2003). Telephone versus face-to-face interviewing of national probability samples with long questionnaires. Public Opinion Quarterly, 67, 79-125.

Ladouceur, R., Jacques, C., Chevalier, S., Sevigny, S., and Hamel, D. (2005). Prevalence of pathological gambling in Quebec in 2002. Canadian Journal of Psychiatry, 50 (8), 451-6.

Lesieur, H.R., \& Blume, S.B. (1987). The South Oaks Gambling Screen (SOGS): A new instrument for the identification of pathological gamblers. American Journal of Psychiatry, 144, 1184-1188.

Lievesley, D. (1988). Unit Non-Response in Interview Surveys. Unpublished working paper, Social and Community Planning Research, London. Cited in Groves (2006).

Little, Roderick, and Sonya Vartivarian. (2003). On Weighting the Rates in Non-Response Weights" Statistics in Medicine 22:1589-99.

Rush, B., Adlaf, E., Veldhuizen, S., Corea, L., and Vince, S. (2005). Assessing the geo-spatial association in Ontario between the prevalence of problem gambling, treatment availability and help seeking. Final Report to the Ontario Problem Gambling Research Centre, September 2005.

Schaeffer, N.C. (2000). Asking questions about threatening topics: A selective overview. In A.A. Stone and J.S. Turkkan (eds.), The Science of Self-Report: Implications for Research and Practice (pp 105-121). Mahwah, NJ: Erlbaum.

Shaffer, H.J., and Hall, M.N. (2001). Updating and refining meta-analytic prevalence estimates of disordered gambling behavior in the United States and Canada. Canadian Journal of Public Health, 92 (3), 168-172.

St-Pierre, M. and Béland, Y. (2004). Mode effects in the Canadian Community Health Survey: a Comparison of CAPI and CATI. 2004 Proceedings of the American Statistical Association Meeting, Survey Research Methods. Toronto, Canada: American Statistical Association.

Smith, F. (1983). On the Validity of Inferences from Non-Random Samples. Journal of the Royal Statistical Society, Series A 146:394-403.

Tourangeau, R., and Yan, T. (2007). Sensitive questions in surveys. Psychological Bulletin, 133 (5), 859-883. 
van der Heijden, P. G. M., Van Gils, G., Bouts, J., and Hox, J. J. (2000). A comparison of randomized response, computer assisted interview, and face-to-face direct questioning: Eliciting sensitive information in the context of welfare and unemployment benefit. Sociological Methods and Research, 28, 505-537.

Volberg, R.A. (2007). Population Surveys. In Research and Measurement Issues in Gambling Studies, Smith, G., Hodgins, D. and Williams, R.J. (eds). p. 33-51. San Diego, CA: Elsevier.

Williams, R.J., Connolly, D., Wood, R.T., and Nowatzki, N. (2006). Gambling and problem gambling in a sample of university students. Journal of Gambling Issues, 16, 1-14.

Williams, R.J., \& Wood, R.T. (2007). The proportion of Ontario gambling revenue derived from problem gamblers. Canadian Public Policy, 33(3), 367-388.

Wood, R.T. and Williams, R.J. (2007). How much money do you spend on gambling? The comparative validity of question wordings used to assess gambling expenditure. International Journal of Social Research Methodology: Theory and Practice, 10 (1), 63-77.

Wood, R.T. \& Williams, R.J. (2009). Internet Gambling: Prevalence, Patterns, Problems, and Policy Options. Final Report prepared for the Ontario Problem Gambling Research Centre, Guelph, Ontario. January 5, 2009. 
Figure 1. Kitchener Census Metropolitan Area (CMA).

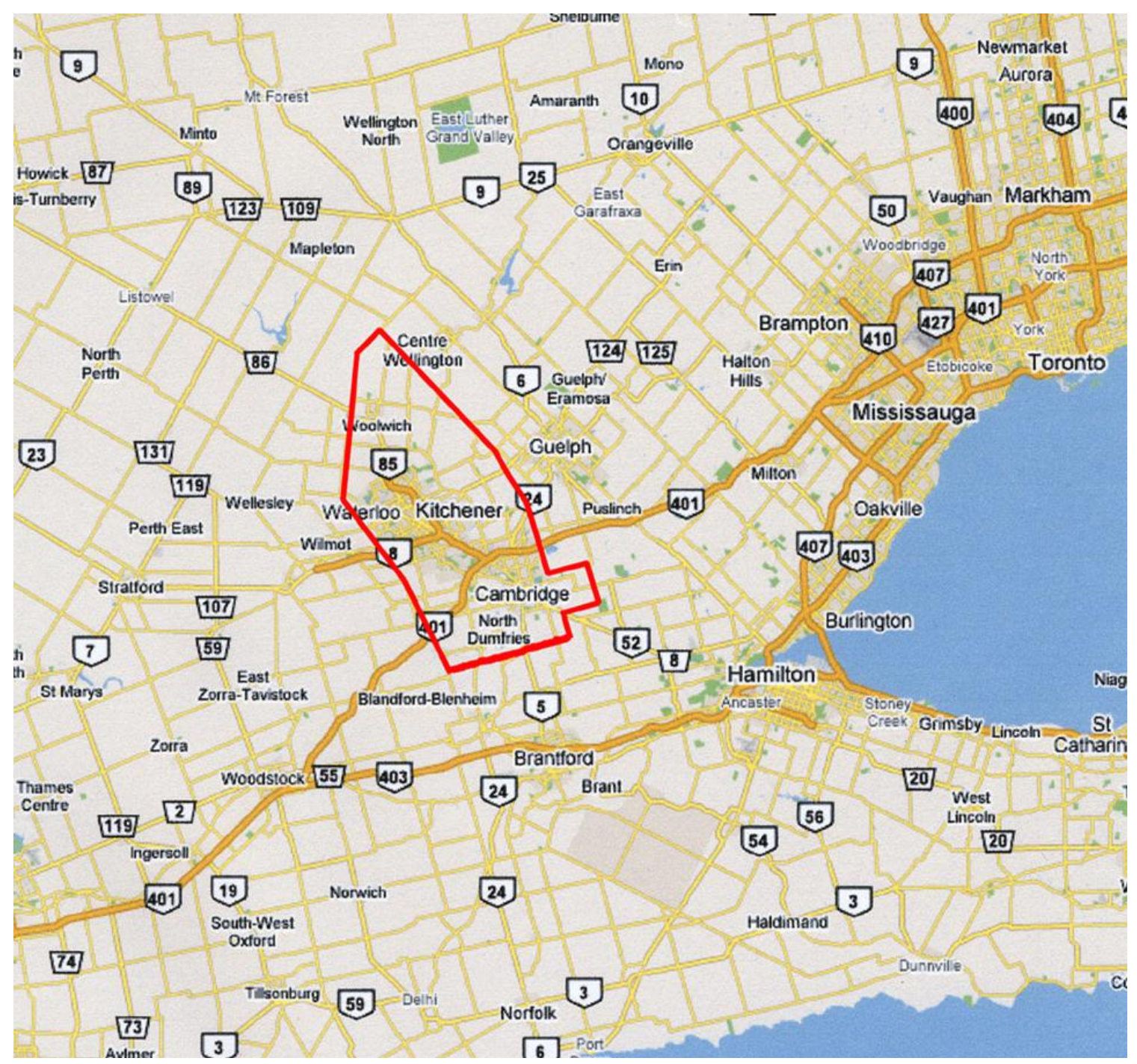


Table 1. Obtained Prevalence of Problem Gambling in Canada.

\begin{tabular}{|c|c|c|c|c|c|c|c|}
\hline & 2000 & 2001 & 2002 & 2003 & 2004 & 2005 & 2006 \\
\hline British Columbia & & & $\begin{array}{l}3.8 \% \\
1.9 \% \\
\end{array}$ & & & & \\
\hline Alberta & & $5.2 \%$ & $2.2 \%$ & & & & \\
\hline Saskatchewan & & $5.9 \%$ & $2.9 \%$ & & & & \\
\hline Manitoba & & $3.4 \%$ & $2.9 \%$ & & & & \\
\hline Ontario & & $3.8 \%$ & $2.0 \%$ & $4.8 \%$ & & $3.4 \%$ & \\
\hline Quebec & & & $\begin{array}{l}1.8 \% \\
1.7 \% \\
\end{array}$ & & & & \\
\hline New Brunswick & & $3.2 \%$ & $1.5 \%$ & & & $1.1 \%$ & \\
\hline Nova Scotia & & & $2.0 \%$ & $2.1 \%$ & & & \\
\hline Prince Edward Island & & & $1.9 \%$ & & & $1.6 \%$ & \\
\hline Newfoundland & & & $1.9 \%$ & & & $3.4 \%$ & \\
\hline CANADA & & & $2.0 \%$ & & & & \\
\hline
\end{tabular}

Note. Bolded numbers reflect figures obtained from the CCHS 1.2 (2002) and CCHS 3.1 (2005) surveys administered by Statistics Canada. Because the gambling module was an optional component of the CCHS 2.1 (in 2003) and CCHS 3.1 cycles, only a small number of health regions included it. In CCHS 2.1 only eight health regions in Ontario and Saskatchewan utilized this module which does not allow the calculation of overall provincial rates. In CCHS 3.1 all health regions in New Brunswick (but no health regions in any other province) used it, allowing the calculation of a provincial rate.

Note. Figures represent the past year rate of moderate plus severe problem gambling from the Canadian Problem Gambling Index (Ferris and Wynne, 2001). 
Table 2. CPGI Categorizations as a Function of Administration Format and Survey Description: Unweighted Results

\begin{tabular}{|c|c|c|c|c|c|c|c|c|}
\hline & $\begin{array}{l}\text { Completes/ } \\
\text { (Completes } \\
\text { + Refusals) }\end{array}$ & $\begin{array}{c}\text { Total } \\
\text { Completes }\end{array}$ & $\begin{array}{c}\text { Nongambler } \\
\text { (N) }\end{array}$ & $\begin{array}{c}\text { NonProblem } \\
\text { Gambler } \\
(\mathrm{NP})\end{array}$ & $\begin{array}{l}\text { Low Risk } \\
\text { Gambler } \\
\text { (LR) }\end{array}$ & $\begin{array}{c}\text { Moderate } \\
\text { Problem } \\
\text { Gambler } \\
(\mathrm{MP}) \\
\end{array}$ & $\begin{array}{c}\text { Severe } \\
\text { Problem } \\
\text { Gambler } \\
(\mathrm{SP})\end{array}$ & $\begin{array}{l}\text { Significant Table and Column } \\
\text { Proportion Differences }\end{array}$ \\
\hline $\begin{array}{l}\text { Telephone Format } \\
\text { (T) }\end{array}$ & $35.7 \%$ & 1513 & $\begin{array}{c}454 \\
30.0 \%\end{array}$ & $\begin{array}{c}940 \\
62.1 \%\end{array}$ & $\begin{array}{c}91 \\
6.0 \%\end{array}$ & $\begin{array}{c}22 \\
1.5 \%\end{array}$ & $\begin{array}{c}6 \\
0.4 \%\end{array}$ & \multirow{2}{*}{$\begin{array}{l}5 \times 2 \text { Table: } p=.000 \\
\text { Column Proportions: N, LR, MP }\end{array}$} \\
\hline $\begin{array}{l}\text { Face-to-Face Format } \\
\text { (F) }\end{array}$ & $48.6 \%$ & 1515 & $\begin{array}{c}381 \\
25.1 \%\end{array}$ & $\begin{array}{c}947 \\
62.5 \%\end{array}$ & $\begin{array}{l}126 \\
8.3 \%\end{array}$ & $\begin{array}{c}54 \\
3.6 \%\end{array}$ & $\begin{array}{c}7 \\
0.5 \%\end{array}$ & \\
\hline $\begin{array}{l}\text { Gambling Survey } \\
\text { (GS) }\end{array}$ & $42.0 \%$ & 1548 & $\begin{array}{c}391 \\
25.3 \%\end{array}$ & $\begin{array}{c}964 \\
62.3 \%\end{array}$ & $\begin{array}{l}131 \\
8.5 \%\end{array}$ & $\begin{array}{c}54 \\
3.5 \%\end{array}$ & $\begin{array}{c}8 \\
0.5 \%\end{array}$ & \multirow{2}{*}{$\begin{array}{l}5 \times 2 \text { Table: } p=.000 \\
\text { Column Proportions: N, LR, MP }\end{array}$} \\
\hline $\begin{array}{l}\text { Health and Recreation } \\
\text { Survey (HS) }\end{array}$ & $42.3 \%$ & 1480 & $\begin{array}{c}444 \\
30.0 \%\end{array}$ & $\begin{array}{c}923 \\
62.4 \%\end{array}$ & $\begin{array}{c}86 \\
5.8 \%\end{array}$ & $\begin{array}{l}22 \\
1.5 \%\end{array}$ & $\begin{array}{l}5 \\
0.3 \%\end{array}$ & \\
\hline $\mathrm{T}-\mathrm{GS}$ & $35.0 \%$ & 758 & $\begin{array}{c}200 \\
26.4 \%\end{array}$ & $\begin{array}{c}482 \\
63.6 \%\end{array}$ & $\begin{array}{c}56 \\
7.4 \%\end{array}$ & $\begin{array}{c}16 \\
2.1 \%\end{array}$ & $\begin{array}{c}4 \\
0.5 \%\end{array}$ & \multirow{2}{*}{$\begin{array}{l}5 \times 2 \text { Table: } p=.002 \\
\text { Column Proportions: N, LR, MP }\end{array}$} \\
\hline $\mathrm{T}-\mathrm{HS}$ & $36.4 \%$ & 755 & $\begin{array}{c}254 \\
33.6 \%\end{array}$ & $\begin{array}{c}458 \\
60.7 \%\end{array}$ & $\begin{array}{c}35 \\
4.6 \%\end{array}$ & $\begin{array}{c}6 \\
0.8 \%\end{array}$ & $\begin{array}{c}2 \\
0.3 \%\end{array}$ & \\
\hline F - GS & $49.0 \%$ & 790 & $\begin{array}{c}191 \\
24.2 \%\end{array}$ & $\begin{array}{c}482 \\
61.0 \%\end{array}$ & $\begin{array}{c}75 \\
9.5 \%\end{array}$ & $\begin{array}{c}38 \\
4.8 \%\end{array}$ & $\begin{array}{c}4 \\
0.5 \%\end{array}$ & \multirow{2}{*}{$\begin{array}{l}5 \times 2 \text { Table: } p=.025 \\
\text { Column Proportions: MP }\end{array}$} \\
\hline $\mathrm{F}-\mathrm{HS}$ & $48.1 \%$ & 725 & $\begin{array}{c}189 \\
26.1 \%\end{array}$ & $\begin{array}{c}466 \\
64.3 \%\end{array}$ & $\begin{array}{c}51 \\
7.0 \%\end{array}$ & $\begin{array}{c}16 \\
2.2 \%\end{array}$ & $\begin{array}{c}3 \\
0.4 \%\end{array}$ & \\
\hline $\mathrm{T}-\mathrm{GS}$ & $35.0 \%$ & 758 & $\begin{array}{c}200 \\
26.4 \%\end{array}$ & $\begin{array}{c}481 \\
63.5 \%\end{array}$ & $\begin{array}{c}56 \\
7.4 \%\end{array}$ & $\begin{array}{c}16 \\
2.1 \%\end{array}$ & $\begin{array}{c}4 \\
0.5 \%\end{array}$ & \multirow{2}{*}{$\begin{array}{l}5 \times 2 \text { Table: } p=.024 \\
\text { Column Proportions: MP }\end{array}$} \\
\hline F - GS & $49.0 \%$ & 790 & $\begin{array}{c}191 \\
24.2 \%\end{array}$ & $\begin{array}{c}482 \\
61.0 \%\end{array}$ & $\begin{array}{c}75 \\
9.5 \%\end{array}$ & $\begin{array}{c}38 \\
4.8 \%\end{array}$ & $\begin{array}{c}4 \\
0.5 \%\end{array}$ & \\
\hline $\mathrm{T}-\mathrm{HS}$ & $36.4 \%$ & 755 & $\begin{array}{c}254 \\
33.6 \%\end{array}$ & $\begin{array}{c}458 \\
60.7 \%\end{array}$ & $\begin{array}{c}35 \\
4.6 \%\end{array}$ & $\begin{array}{c}6 \\
0.8 \%\end{array}$ & $\begin{array}{c}2 \\
0.3 \%\end{array}$ & \multirow{2}{*}{$\begin{array}{l}5 \times 2 \text { Table: } p=.002 \\
\text { Column Proportions: N, LR, MP }\end{array}$} \\
\hline $\mathrm{F}-\mathrm{HS}$ & $48.1 \%$ & 725 & $\begin{array}{c}190 \\
26.2 \%\end{array}$ & $\begin{array}{c}465 \\
64.1 \%\end{array}$ & $\begin{array}{c}51 \\
7.0 \%\end{array}$ & $\begin{array}{c}16 \\
2.2 \%\end{array}$ & $\begin{array}{c}3 \\
0.4 \%\end{array}$ & \\
\hline
\end{tabular}


Table 3. CPGI Categorizations as a Function of Administration Format and Survey Description: Data Weighted by Age x Gender x Immigrant Status to Approximate Statistics Canada figures for the Kitchener CMA in 2006.

\begin{tabular}{|c|c|c|c|c|c|c|c|c|}
\hline & $\begin{array}{l}\text { Completes/ } \\
\text { (Completes } \\
\text { + Refusals) }\end{array}$ & $\begin{array}{c}\text { Total } \\
\text { Completes }\end{array}$ & $\begin{array}{c}\text { Nongambler } \\
(\mathrm{N})\end{array}$ & $\begin{array}{l}\text { NonProblem } \\
\text { Gambler } \\
\text { (NP) }\end{array}$ & $\begin{array}{l}\text { Low Risk } \\
\text { Gambler } \\
\text { (LR) }\end{array}$ & $\begin{array}{l}\text { Moderate } \\
\text { Problem } \\
\text { Gambler } \\
(\mathrm{MP})\end{array}$ & $\begin{array}{c}\text { Severe } \\
\text { Problem } \\
\text { Gambler } \\
(\mathrm{SP})\end{array}$ & $\begin{array}{l}\text { Significant Table and Column } \\
\text { Proportion Differences }\end{array}$ \\
\hline $\begin{array}{l}\text { Telephone Format } \\
\text { (T) }\end{array}$ & $35.7 \%$ & 1518 & $\begin{array}{c}447 \\
29.4 \%\end{array}$ & $\begin{array}{c}946 \\
62.3 \%\end{array}$ & $\begin{array}{c}95 \\
6.3 \%\end{array}$ & $\begin{array}{c}24 \\
1.6 \%\end{array}$ & $\begin{array}{c}6 \\
0.4 \%\end{array}$ & \multirow{2}{*}{$\begin{array}{l}5 \times 2 \text { Table: } p=.056 \\
\text { Column Proportions: N, MP }\end{array}$} \\
\hline $\begin{array}{l}\text { Face-to-Face Format } \\
\text { (F) }\end{array}$ & $48.6 \%$ & 1528 & $\begin{array}{c}394 \\
25.8 \%\end{array}$ & $\begin{array}{c}984 \\
64.4 \%\end{array}$ & $\begin{array}{c}102 \\
6.7 \%\end{array}$ & $\begin{array}{c}42 \\
2.7 \%\end{array}$ & $\begin{array}{c}6 \\
0.4 \%\end{array}$ & \\
\hline $\begin{array}{l}\text { Gambling Survey } \\
\text { (GS) }\end{array}$ & $42.0 \%$ & 1560 & $\begin{array}{c}390 \\
25.0 \%\end{array}$ & $\begin{array}{c}988 \\
63.3 \%\end{array}$ & $\begin{array}{c}127 \\
8.1 \%\end{array}$ & $\begin{array}{c}46 \\
2.9 \%\end{array}$ & $\begin{array}{c}9 \\
0.6 \%\end{array}$ & \multirow{2}{*}{$\begin{array}{l}5 \times 2 \text { Table: } p=.000 \\
\text { Column Proportions: N, LR, MP }\end{array}$} \\
\hline $\begin{array}{l}\text { Health and Recreation } \\
\quad \text { Survey (HS) }\end{array}$ & $42.3 \%$ & 1488 & $\begin{array}{c}452 \\
30.4 \%\end{array}$ & $\begin{array}{c}943 \\
63.4 \%\end{array}$ & $\begin{array}{c}70 \\
4.7 \%\end{array}$ & $\begin{array}{c}20 \\
1.3 \%\end{array}$ & $\begin{array}{c}3 \\
0.2 \%\end{array}$ & \\
\hline $\mathrm{T}-\mathrm{GS}$ & $35.0 \%$ & 759 & $\begin{array}{c}195 \\
25.7 \%\end{array}$ & $\begin{array}{c}482 \\
63.5 \%\end{array}$ & $\begin{array}{c}60 \\
7.9 \%\end{array}$ & $\begin{array}{c}18 \\
2.4 \%\end{array}$ & $\begin{array}{c}4 \\
0.5 \% \\
\end{array}$ & \multirow{2}{*}{$\begin{array}{l}5 \times 2 \text { Table: } p=.000 \\
\text { Column Proportions: N, LR, MP }\end{array}$} \\
\hline $\mathrm{T}-\mathrm{HS}$ & $36.4 \%$ & 759 & $\begin{array}{c}252 \\
33.2 \%\end{array}$ & $\begin{array}{c}464 \\
61.1 \%\end{array}$ & $\begin{array}{c}35 \\
4.6 \%\end{array}$ & $\begin{array}{c}6 \\
0.8 \%\end{array}$ & $\begin{array}{c}2 \\
0.3 \%\end{array}$ & \\
\hline $\mathrm{F}-\mathrm{GS}$ & $49.0 \%$ & 801 & $\begin{array}{c}195 \\
24.3 \%\end{array}$ & $\begin{array}{c}506 \\
63.2 \%\end{array}$ & $\begin{array}{c}67 \\
8.4 \%\end{array}$ & $\begin{array}{c}28 \\
3.5 \%\end{array}$ & $\begin{array}{c}5 \\
0.6 \% \\
\end{array}$ & \multirow{2}{*}{$\begin{array}{l}5 \times 2 \text { Table: } p=.009 \\
\text { Column Proportions: LR }\end{array}$} \\
\hline $\mathrm{F}-\mathrm{HS}$ & $48.1 \%$ & 730 & $\begin{array}{c}200 \\
27.4 \% \\
\end{array}$ & $\begin{array}{c}479 \\
65.6 \% \\
\end{array}$ & $\begin{array}{c}35 \\
4.8 \% \\
\end{array}$ & $\begin{array}{c}14 \\
1.9 \% \\
\end{array}$ & $\begin{array}{c}2 \\
0.3 \% \\
\end{array}$ & \\
\hline $\mathrm{T}-\mathrm{GS}$ & $35.0 \%$ & 759 & $\begin{array}{c}195 \\
25.7 \%\end{array}$ & $\begin{array}{c}482 \\
63.5 \%\end{array}$ & $\begin{array}{c}60 \\
7.9 \%\end{array}$ & $\begin{array}{c}18 \\
2.4 \%\end{array}$ & $\begin{array}{c}4 \\
0.5 \%\end{array}$ & \multirow{2}{*}{$\begin{array}{l}5 \times 2 \text { Table: } p=.713 \\
\text { Column Proportions: none }\end{array}$} \\
\hline F - GS & $49.0 \%$ & 801 & $\begin{array}{c}195 \\
24.3 \% \\
\end{array}$ & $\begin{array}{c}506 \\
63.2 \% \\
\end{array}$ & $\begin{array}{c}67 \\
8.4 \% \\
\end{array}$ & $\begin{array}{c}28 \\
3.5 \% \\
\end{array}$ & $\begin{array}{c}5 \\
0.6 \% \\
\end{array}$ & \\
\hline $\mathrm{T}-\mathrm{HS}$ & $36.4 \%$ & 759 & $\begin{array}{c}252 \\
33.3 \%\end{array}$ & $\begin{array}{c}464 \\
61.2 \%\end{array}$ & $\begin{array}{c}35 \\
4.6 \%\end{array}$ & $\begin{array}{c}6 \\
0.7 \%\end{array}$ & $\begin{array}{c}2 \\
0.3 \%\end{array}$ & \multirow{2}{*}{$\begin{array}{l}5 \times 2 \text { Table: } p=.065 \\
\text { Column Proportions: N, MP }\end{array}$} \\
\hline $\mathrm{F}-\mathrm{HS}$ & $48.1 \%$ & 730 & $\begin{array}{c}200 \\
27.4 \%\end{array}$ & $\begin{array}{c}479 \\
65.6 \%\end{array}$ & $\begin{array}{c}35 \\
4.8 \%\end{array}$ & $\begin{array}{c}14 \\
1.9 \%\end{array}$ & $\begin{array}{c}2 \\
0.3 \%\end{array}$ & \\
\hline
\end{tabular}


Table 4. 2 Way ANOVA Results on Raw Scores and Categorical Rates for Each of the Four Assessment Instruments

\begin{tabular}{|c|c|l|l|l|}
\hline & $\begin{array}{c}\text { Corrective } \\
\text { Weighting for Age } \\
\text { x Gender } \\
\text { Immigrant Status }\end{array}$ & \multicolumn{1}{|c|}{ Administration Format } & \multicolumn{1}{|c|}{ Survey Description } & \multicolumn{1}{|c|}{ Format x Description } \\
\hline CPGI Total Score & No & $F(1,3017)=8.27, p=.004$ & $F(1,3017)=10.35, p=.001$ & $F(1,3017)=.16, p=.688$ \\
\hline CPGI Total Score & Yes & $F(1,3063)=.30, p=.586$ & $F(1,3063)=11.6, p=.001$ & $F(1,3063)=.04, p=.841$ \\
\hline CPGI Categories & No & $F(1,3024)=21.27, p=.000$ & $F(1,3024)=22.50, p=.000$ & $F(1,3024)=.49, p=.484$ \\
\hline CPGI Categories & Yes & $F(1,3067)=4.90, p=.027$ & $F(1,3067)=31.12, p=.000$ & $F(1,3067)=1.69, p=.194$ \\
\hline SOGS Total Score & No & $F(1,3024)=5.09, p=.024$ & $F(1,3024)=6.48, p=.011$ & $F(1,3024)=.004, p=.950$ \\
\hline SOGS Total Score & Yes & $F(1,3067)=.50, p=.480$ & $F(1,3067)=3.99, p=.046$ & $F(1,3067)=3.46, p=.063$ \\
\hline SOGS Categories & No & $F(1,3024)=12.11, p=.001$ & $F(1,3024)=10.54, p=.001$ & $F(1,3024)=1.45, p=.229$ \\
\hline SOGS Categories & Yes & $F(1,3067)=4.87, p=.027$ & $F(1,3067)=11.67, p=.001$ & $F(1,3067)=5.40, p=.020$ \\
\hline NODS Total Score & No & $F(1,3024)=18.28, p=.000$ & $F(1,3024)=7.39, p=.007$ & $F(1,3024)=.06, p=.805$ \\
\hline NODS Total Score & Yes & $F(1,3067)=4.22, p=.040$ & $F(1,3067)=12.58, p=.000$ & $F(1,3067)=.18, p=.674$ \\
\hline NODS Categories & No & $F(1,3024)=25.45, p=.000$ & $F(1,3024)=13.79, p=.000$ & $F(1,3024)=.93, p=.334$ \\
\hline NODS Categories & Yes & $F(1,3067)=8.23, p=.004$ & $F(1,3067)=22.00, p=.000$ & $F(1,3067)=1.56, p=.212$ \\
\hline PPGM Total Score & No & $F(1,3024)=14.88, p=.000$ & $F(1,3024)=8.81, p=.003$ & $F(1,3024)=.90, p=.342$ \\
\hline PPGM Total Score & Yes & $F(1,3067)=2.85, p=.091$ & $F(1,3067)=10.69, p=.001$ & $F(1,3067)=.26, p=.612$ \\
\hline
\end{tabular}

SOGS Categories were Non-Gambler; Non-Problem Gambler (score of 0 -2); Problem Gambler (score of 3 - 4); Probable Pathological Gambler (score of 5+). NODS Categories were Non-Gambler; Type B Gambler (score of 0); Type C Gambler (score of 1 -2); Type D Gambler (score of 3 -4).

PPGM is still under development and does not yet have categorical cut-offs. 